\title{
Dietary habits in the endangered Bearded Vulture Gypaetus barbatus from Upper Pleistocene to modern times in Spain: a paleobiological conservation perspective
}

\author{
ANTONI MARGALIDA and ANA B. MARÍN-ARROYO
}

\begin{abstract}
Summary
Although most Old World vulture species are declining or threatened in Asia and Africa, in Europe healthy vulture populations still exist. However, recent application of sanitary legislation that has greatly reduced the availability of animal carcasses is now a concern for conservationists. Until now, no studies have been undertaken to determine long-term dietary shifts in these species in Europe, but such studies are essential to optimising the resources invested in conservation and to anticipating the ecological needs of the target species. Here, we present a first attempt to examine the dietary variation in the Bearded Vulture Gypaetus barbatus from the late Pleistocene to the present day. Medium-size wild ungulates such as southern chamois Rupicapra pyrenaica, Spanish ibex Capra pyrenaica, red deer Cerous elaphus and roe deer Capreolus capreolus dominate the diet during the Pleistocene supporting the hypothesis that Bearded Vulture distribution was largely determined by the presence of such species. On the contrary, domestic species, such as sheep Ovis aries and goat Capra hircus, are the most common taxa in the diet in modern and historic periods. The actual dependence of the species on livestock, along with a restrictive sanitary legislation, threaten the conservation of this and other endangered avian scavengers in Europe. This new paleobiological conservation perspective confirms that efforts to establish a self-sustaining Bearded Vulture population should be enhanced by the widespread availability of medium-sized wild ungulates and by the presence of extensive and traditional grazing practices.
\end{abstract}

\section{Introduction}

Despite the great effort of conservation projects, several Old World vultures are still endangered, mainly due to previously unexpected threats, such as the ingestion of veterinary drugs (Green et al. 2006, Naidoo et al. 2009), the appearance of illegal poisoning practices (Hernández and Margalida 2008, 2009, Virani et al. 2011, Margalida 2012) and the restrictions on animal disposal put in place by sanitary authorities such as those imposed by the European Union with the appearance of bovine spongiform encephalopathy (Donázar et al. 2009, Margalida et al. 2010, 2012). Given this scenario, a detailed characterisation of the trophic ecology and long-term dietary shifts of these species must be an important tool for conservation projects based on the management of food resources (Newsome et al. 2010). In addition, this information can be especially important in understanding extinction risks (Dietl and Flessa 2011) and can provide relevant insights on the ability of the species to adapt to changing environmental conditions, allowing us to infer their possible future trends.

Although geo-historical data are essential to optimisation and application of successful conservation strategies, the majority of conservation-related research to date is based on short timescales 
(Willis and Birks 2006, Froyd and Willis 2008, Dietl and Flesa 2011). To our knowledge, accurate, long-term studies on dietary shifts are only available for the New World California Condor Gymnogyps californianus (Chamberlain et al. 2005) and Bald Eagle Haliaeetus leucocephalus (Newsome et al. 2010). Here, we present the first attempt to reconstruct the long-term diet for the Bearded Vulture Gypaetus barbatus in Spain, a highly threatened bird of prey which is now the subject of great conservation efforts. The diachronic evolution of its diet from the late Pleistocene to the present day is characterised by means of the anatomical and taxonomical identification of faunal assemblages, as a result of the study of the bone remains recovered from a prehistoric nesting site, three historic nests (occupied between 1940-1950 located in Asturias, Murcia and Andalusia) and three modern sites (located in Catalonia).

The prehistoric distribution of the Bearded Vulture was probably similar to that of the $19^{\text {th }}$ century (Arribas 2004) before massive human overpopulation at the end of the second half of the twentieth century. Unfortunately the current population of the Bearded Vulture has changed since then, with increasingly reduced distribution and population size due to direct persecution, mainly through poisoning and shooting (Hiraldo et al. 1979, Margalida 2010). Because this species delivers food directly to the nest, bone remains accumulated there are a direct reflection of its diet, allowing us to make comparisons between periods without apparent bias. The ultimate aim of the data presented here is to provide a new tool for the development of future management strategies and the optimisation of resources in vulture conservation policies.

\section{Material and Methods}

The study species

The Bearded Vulture is the only vertebrate with a bone-dominated diet. For each $100 \mathrm{~g}$ of bone, this species absorbs $387 \mathrm{KJ}$ compared to the $44 \mathrm{O} \mathrm{KJ}$ of a purely meat-based diet, suggesting that, due to its high fat content, this diet is energetically feasible (Houston and Copsey 2004). The European Bearded Vulture population is currently limited to the Pyrenees (France and Spain), Corsica, Crete and the Alps, with breeding populations estimated at only 170 territories in 2011 (A. M. unpubl. data).

\section{Bone collection}

Bones were gathered from modern and historical nests in Spain as well as from a Pleistocene cave where evidence of nesting Bearded Vultures has been identified (Figure 1). Although the study is based on different geographical regions, data obtained seems representative of the diet of the species in the Iberian Peninsula according to the literature (Hiraldo et al. 1979, Marín-Arroyo et al. 2009, Margalida 2010). El Mirón Cave (northern Spain; Marín-Arroyo et al. 2009), is located on a vertical cliff of limestone at Monte Pando (eastern Cantabria) and its entrance is a cornice along its walls overlooking the central vestibule at a considerable height. This is a suitable place for nests and could explain the eventual accumulation of bones below due to falling bones and nest decomposition. Additionally, historical bones were obtained from three ancient nests occupied by Bearded Vultures in southern $\left(\mathrm{H}_{1}\right.$ and $\left.\mathrm{H}_{2}\right)$ and northern $\left(\mathrm{H}_{3}\right)$ Spain during 1940-1950 (Margalida et al. 2009b). Finally, bones from three modern nests were collected during visits by one of the authors (A. M.), to three current sites in the Pyrenees during the summer of 2008 (M1, $\mathrm{M}_{2}$ and $\mathrm{M}_{3}$ ).

Regarding chronology, ungulate bone remains recovered at El Mirón Cave belong to a late Upper Pleistocene deposit dated between 14,000-10,000 BP (Marín-Arroyo et al. 2009). Only bones with digestive traces, similar to those observed in current experimental taphonomic studies with wild and captive Bearded Vultures were attributed to this species at this site (Marín-Arroyo and Margalida 2012). They were the result of long bone regurgitation together with hair and hooves, from which keratin cannot be easily digested, and the foot remains (metapodials plus 


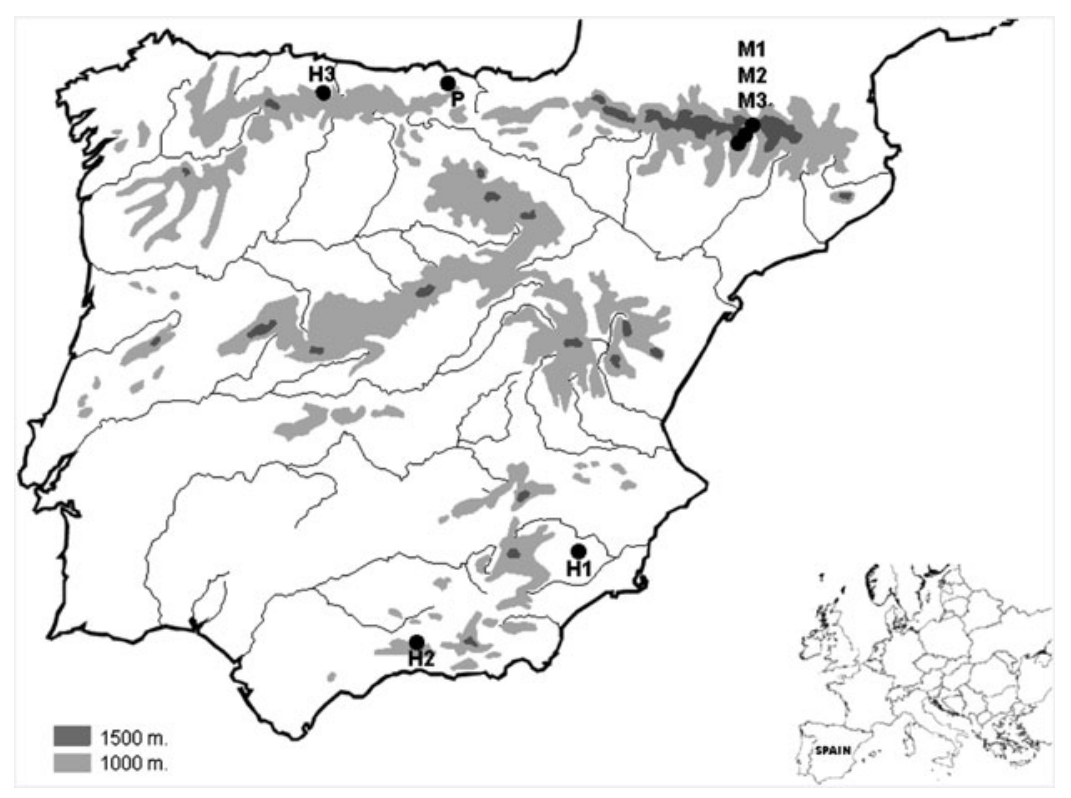

Figure 1 . Study area showing the locality of the nest-sites in which bone remains were collected. Prehistoric (P), Historic ( $\mathrm{H}_{1}, \mathrm{H}_{2}$ and $\left.\mathrm{H}_{3}\right)$ and Modern sites ( $\mathrm{M}_{1}, \mathrm{M}_{2}$ and $\mathrm{M}_{3}$ ).

phalanges) attached to them. After a detailed taphonomic analysis, none of these regurgitated bones were identified as originating from carnivore activity as no gnawing marks were identified. In addition, they do not display any cut marks that could link them to human consumption (Marín-Arroyo 2010). It is likely, however, that the site may hold more fossils brought by Bearded Vultures but without distinctive features. As the cave was also alternately used by human groups in the past, in order to avoid any bias due to incorrect attribution, only the remains clearly identified as the product of Bearded Vulture activities have been used here.

\section{Taxonomic identification}

The prey remains collected from Pleistocene, historic and modern nests were identified with the help of osteological reference collections (Sociedad de Ciencias Aranzadi, San Sebastián, Spain and our own collections). Distinctive morphological features together with bone surface aspect and cortical thickness were used. Because mammals constitute $93 \%$ of the Bearded Vulture diet (birds $6 \%$ and reptiles $1 \%$ ) and ungulates comprised $71 \%$ of the mammals identified ( $n=636$ prey items identified through direct observations; Margalida et al. 2009a), only ungulate bones were used in this analysis in order to avoid the probable underestimation of small prey items (e.g. birds, lagomorphs, carnivores and rodents) due to conservation bias as a consequence of the fragility of their bones (Margalida et al. 2007). Concerning the possible biases related to the differential taphonomic preservation of anatomical parts, we previously tested whether the differences in bone density could influence their conservation over time. No relationship between each anatomical element and its bone density value (Lam et al. 2003) was found in any of the periods and nests considered (Mann-Kendall test $P>0.05$ for all samples). Bone remains have been grouped into four taxonomic categories according their size: 1 ) cow Bos spp. (primigenius/ taurus) and horse Equus caballus; 2) red deer Cerous elaphus and wild boar Sus scrofa and pig Sus scrofa var. dom. 3) Spanish ibex Capra pyrenaica, southern chamois Rupicapra pyrenaica, roe deer Capreolus capreolus, 4) sheep Ovis aries and goat Capra hircus. 


\section{Anatomical classification}

To analyse temporal variations in the presence of the anatomical parts represented within the diet, bones were also placed into six anatomical categories: head (including skull, mandible, atlas and axis), ribcage (ribs, sternum and scapula), vertebral column (cervical, thoracic and lumbar vertebrae plus pelvis and sacrum), forelimb (humerus, radius/ulna, carpals and metacarpal), hind limb (femur, tibia, tarsals and metatarsals) and phalanges. This classification takes into account not only the typical anatomical connection but also similar dietary utility in terms of amount of bone grease (Emerson 1990), its percentage of oleic acid (Binford 1978) and the length of the element; see Marín-Arroyo and Margalida (2012) for Bearded Vulture Bone Utility Index.

\section{Statistical analyses}

Chi-squared test were used to discern differences among taxonomic and anatomical preferences over time. Frequencies were compared through contingency tables and values are presented as means $\pm \mathrm{SD}$.

\section{Results}

\section{Taxonomic variation in the diet}

We found significant differences in dietary composition between modern nests $\left(\chi^{2}{ }_{8}=24.28\right.$, $P=0.002)$ and historic nests $\left(\chi_{8}^{2}=21.58, P=0.006\right)$. To avoid pseudo-replication problems, we tested individual nest differences (modern and historic nests) with respect to prehistoric times and in all cases we found significant differences in the diet composition $(P<0.0001$ in all cases). Domestic species, such as Ovis/Capra, were the most common taxa in the diet in modern ( $71.47 \pm 2.75 \%, n=377$ remains) and historic periods $(74.43 \pm 15.52 \%, n=56)$, whereas in the prehistoric period $(n=270$ ) the diet was based principally on medium-sized wild ungulates such as southern chamois/roe deer/Spanish ibex (65.2\%) and red deer (34.8\%) (Figure 2a). In spite of these differences in taxonomic representation between periods, which are obviously due to the absence of domestic species during Pleistocene, the medium mammal size is common to all periods.

\section{Anatomical variation of the skeletal parts selected}

The anatomical composition of the diet (Figure $2 b$ ) showed differences between the skeletal parts found in modern nests $\left(\chi_{10}^{2}=150.36, P<0.0001\right)$ and in historic ones $\left(\chi_{10}^{2}=38.48\right.$, $P<$ 0.0001). To avoid pseudo-replication problems, we tested individual nest differences with respect to prehistoric times and in all cases (individual data of modern $M_{1}, M_{2}$ and $M_{3}$ vs prehistoric and individual data of historic $\mathrm{H}_{1}, \mathrm{H}_{2}$ and $\mathrm{H}_{3}$ vs prehistoric) we found significant differences in anatomical composition $(P<0.0001$ in all cases $)$ showing an important trend towards metapodials + phalanx remains in prehistoric times, whereas in historic and modern nests the skeletal profiles are more heterogeneous (Figure $2 \mathrm{~b}$ ).

\section{Discussion}

Based on their dietary habits, our results suggest that the distribution of European Bearded Vultures from the Pleistocene to the present day is still linked to areas with high availability of medium-sized ungulate carcasses. The dietary shift from wild to domestic species found in historical and modern times is a direct consequence of the reduction of the former in the ecosystem when they were replaced by the latter (Zeder 2008). During prehistoric times, depending on the topographic environment, red deer, Spanish ibex and southern chamois were the most representative species in the diet of Bearded Vultures in Spain. The animal remains found in numerous European prehistoric sites, either with an anthropogenic or paleontological origin, show 

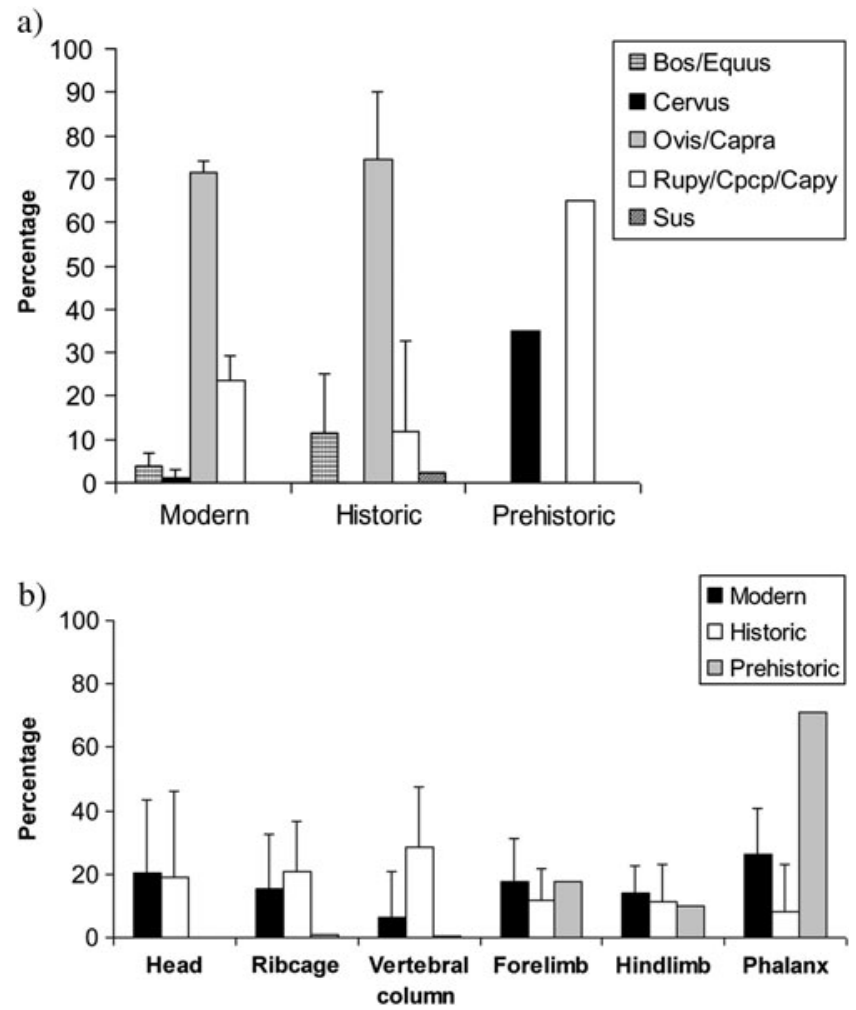

Figure 2. Percentage ( \pm SD) of the different taxonomic (a) and anatomical (b) remains identified in nest sites occupied by bearded vultures according to the three study periods. Bos/Equus: Bos taurus and Equus caballus; Ovis/Capra: Ovis aries and Capra hircus; Rupy/Cpcp/Capy: Rupicapra pyrenaica, Capreolus capreolus and Capra pyrenaica.

that these medium-sized mammals were very abundant in the paleoenvironment and profusely consumed both by hunter-gatherer groups and carnivores, thus providing a constant source for Bearded Vulture scavenging (Marín-Arroyo 2009a). The diet of this scavenger would then have been mainly influenced by the availability of animal resources within its territory, for example red deer and Spanish ibex in the case of El Mirón, a cave located in a rocky environment but also close to broad alluvial plains in the Asón Valley, eastern Cantabria (Marín-Arroyo 2009c). Conversely, in historic and modern nests, sheep and goats were the predominant species. The switch to domestic ungulate consumption observed in historical and modern times reflects the reduction of wild ungulate populations due to hunting and the simultaneous expansion of livestock herding throughout Europe around 10,000-9,000 years BP. The direct persecution of predators (i.e. wolf Canis lupus, brown bear Ursus arctos; Martínez-Abraín et al. 20o9) probably also reduced carcass availability of wild ungulates. Thus, the increase in domestic ungulate populations during the last century would have offered Bearded Vultures an abundant new source of medium-sized carcasses that would have allowed them to expand their habitat beyond northern and more mountainous refugia. However, despite the availability of large-sized mammal carcasses in historic and modern times, these were rarely consumed, which could be related to the bone weight and input obtained. Nevertheless, this fact also led them to depend on livestock.

Taking into account the importance of medium-sized ungulates in the diet of Bearded Vultures (Margalida et al. 2009a, 2010), our data also suggest that medium-sized wild ungulates probably dominated the diet of Bearded Vultures during the Upper-Pleistocene $(62.6 \%$ of the bone 
remains identified), a fact that has important implications for understanding the past geographical range of this species, as it supports the hypothesis that their abundance in certain mountainous areas was largely controlled by the presence of wild ungulates (Hiraldo et al. 1979, Hirzel et al. 2004, Margalida 2010). However, while our study is based on large and medium-sized ungulates (the main species in the diet of Bearded Vultures; Brown and Plug 1990, Thibault et al. 1993, Margalida et al. 2009a,b), small mammals can also be important to the species, principally during the breeding season (i.e. meat content to feed the chick, Margalida et al. 2005, 2009a). These results suggest that the Bearded Vulture is therefore quite specialised and thus highly sensitive to changes in the availability of the resources on which it relies.

Concerning the anatomical preferences, a significant trend towards the consumption of foot limb bones (extremity) remains has been observed. These skeletal parts are easier to transport, swallow and digest and have a higher oleic acid content (Morin 2007, Marín-Arroyo and Margalida, 2012), a fact that again agrees with a positive selection by Bearded Vultures in order to maximise energy balance (Margalida 2008, Margalida et al. 2009a). In prehistoric times this preference is even more intense, probably due to the greater availability of these skeletal elements as a result of human or carnivore discards after hunting, as feet are not very nutritional for them (Marín-Arroyo 2009c).

Apart from the topographic location where the nests were located, it should not be ignored that the inter-nest differences are probably also related to the extraction of remains by other vertebrate scavengers (e.g. corvids) that may profit from them (Margalida and Bertran 2003) and with subsequent taphonomic processes. Nevertheless, a more complete study with a large data set including other Pleistocene and historic nests situated in similar environments should be conducted.

Long-term dietary shifts have important implications for understanding the past distribution of the species and to optimise the development of conservation strategies (Chamberlain et al. 2005). Given the results obtained, conservation concerns related to the application of sanitary legislation that significantly reduces food availability provided by domestic carcasses, as have been discussed recently (Donázar et al. 2009, Margalida et al. 2010, 2011b, 2012), are well-founded. Regions with a limited availability of carcasses of medium-sized wild ungulates and the application of restrictive sanitary legislations that may reduce the number of domestic carcasses, can limit the presence of these species (Donázar et al. 2009, Margalida et al. 2010). Although the specialised diet of the species makes them less sensitive than other vultures that are more meat-dependent (Margalida et al. 2011a, Margalida and Colomer 2012), efforts to establish a self-sustaining Bearded Vulture population may be enhanced by the widespread availability of wild ungulates as an additional food source, and by the presence of extensive and traditional grazing practices (Thibault et al. 1993, Margalida et al. 2009a,b, 2011a).

\section{Acknowledgements}

This paper was written in memory of Prof. Gary R. Bortolotti. We thank Óscar J. Arribas, Gary R. Bortolotti, José A. Donázar, Mark Lewis (Natural History Museum, London), David Ocio and two anonymous reviewers for comments on this manuscript. Ana B. Marín-Arroyo has a contract within the Ramon y Cajal Program (RYC-2011-00695), at the Instituto Internacional de Investigaciones Prehistóricas de Cantabria, University of Cantabria.

\section{References}

Arribas, O. J. (2004) Fauna y paisaje de los Pirineos en la Era Glaciar. Barcelona, Spain: Lynx edicions.

Binford, L. R. (1978) Nunamiut ethnoarchaeology. London, UK: Academic Press.

Brown, C. J. and Plug, I. (1990) Food choice and diet of the Bearded vulture Gypaetus barbatus in Southern Africa. S. Afr. J. Zool. 25: 169-177.

Chamberlain, C. P., Waldbauer, J. R., Fox-Dobbs, K. et al. (2005) Pleistocene to recent dietary shifts in California condors. Proc. Nat. Acad. Sci. USA 102: 16707-16711. 
Dietl, G. P. and Flessa, K. W. (2011) Conservation paleobiology: putting the dead to work. Trends Ecol. Evol. 26: 30-37.

Donázar, J. A., Margalida, A., Carrete, M. and Sánchez-Zapata, J. A. (2009) Too sanitary for vultures. Science 326: 664.

Emerson, A. M. (1990) Archaeological implications of variability in the economic anatomy of Bison bison. Ph.D. Dissertation. Washington: Washington State University.

Froyd, C. A. and Willis, K. J. (2008) Emerging issues in biodiversity and conservation management: the need for a palaeoecological perspective. Quat. Sci. Rev. 27: 1723-1732.

Green, R. E., Taggart, M. A., Das, D., Pain, D. J., Kumar, C. S., Cunningham, A. A. and Cuthbert, R. (2006) Collapse of Asian vulture populations: risk of mortality from residues of the veterinary drug diclofenac in carcasses of treated cattle. J. Appl. Ecol. 43: 949-956.

Hernández, M. and Margalida, A. (2008) Pesticide abuse in Europe: effects on the Cinereous vulture (Aegypius monachus) population in Spain. Ecotoxicology 17: 264-272.

Hernández, M. and Margalida, A. (2009) Poison-related mortality effects in the endangered Egyptian Vulture (Neophron percnopterus) population in Spain: conservation measures. Eur. J. Wildl. Res. 55: 415-423.

Hiraldo, F., Delibes, M. and Calderón, J. (1979) El Quebrantahuesos Gypaetus barbatus (L.). Madrid, Spain: Instituto para la Conservación de la Naturaleza. (Monografía 22).

Hirzel, A. H., Posse, B., Oggier, P. A., Crettenand, Y., Glenz, C. and Arlettaz, R. (2004) Ecological requirements of reintroduced species and the implications for release policy: the case of the bearded vulture J. Appl. Ecol. 41: 1103-1116

Houston, D. C. and Copsey, J. A. (2004) Bone digestion and intestinal morphology of the Bearded Vulture. J. Raptor Res. 28: 73-78.

Lam, Y. M., Pearson, O. M., Marean, C. and Chen, X. (2003) Bone density studies in zooarchaeology. J. Archaeol. Sci. 30: 17011708.

Margalida, A. (2008) Bearded vultures (Gypaetus barbatus) prefer fatty bones. Behav. Ecol. Sociobiol. 63: 187-193.
Margalida, A. (2010) Conservation biology of the last and largest natural population of the European bearded vulture Gypaetus barbatus (Linnaeus, 1758). Ph.D. Thesis. Bern: University of Bern.

Margalida, A. (2012) Baits, budget cuts: a deadly mix. Science 338: 192.

Margalida, A. and Bertran, J. (2003) Inter and intraspecific kleptoparasitic interactions of the Bearded Vulture Gypaetus barbatus at nesting areas. J. Raptor Res. 37: 157-160.

Margalida, A., Bertran, J. and Boudet, J. (2005) Assessing the diet of nestling Bearded Vultures: a comparison between direct observation methods. J. Field Ornithol. 76: 40-45.

Margalida, A., Bertran, J. and Heredia, R. (2009a) Diet and food preferences of the endangered Bearded Vulture Gypaetus barbatus: a basis for their conservation. Ibis 151: $235-243$.

Margalida, A., Campión, D. and Donázar, J. A. (2011b) European vultures' altered behaviour. Nature 480: 457.

Margalida, A., Carrete, M., Sánchez-Zapata, J. A. and Donázar, J. A. (2012) Good news for European vultures. Science 335: 284.

Margalida, A., Colomer, M. A. and Sanuy, D. (2011a) Can wild ungulate carcasses provide enough biomass to maintain avian scavenger populations? An empirical assessment using a bio-inspired computational model. PLoS One 6: e20248.

Margalida, A. and Colomer, M.A. (2012) Modelling the effects of sanitary policies on European vulture conservation. Sci. Rep. 2: 753 .

Margalida, A., Donázar, J. A., Bustamante, J., Hernández, F. J. and Romero-Pujante, M. (2008) Application of a predictive model to detect long-term changes in nest-site selection in the Bearded Vulture Gypaetus barbatus: conservation in relation to territory shrinkage. Ibis 150: 242-249.

Margalida, A., Donázar, J. A., Carrete, M. and Sánchez-Zapata, J. A. (2010) Sanitary versus environmental policies: fitting together two pieces of the puzzle of European vulture conservation. J. Appl. Ecol. 47: 931-935.

Margalida, A., Mañosa, S., Bertran, J. and García, D. (2007) Biases in studying the diet of the Bearded vulture. J. Wildl. Manage. 71: 1621-1625. 
Margalida, A., Sánchez-Zapata, J. A., Eguía, S., Marín Arroyo, A. B., Hernández, F. J. and Bautista, J. (2009b) Assessing the diet of breeding bearded vultures (Gypaetus barbatus) in mid-2oth century in Spain: A comparison to recent data and implications for conservation. Eur. J. Wildl. Res. 55: 443-447.

Marín-Arroyo, A. B. (2009a) The human use of the montane zone of Cantabrian Spain during the Late Glacial: faunal evidence from El Mirón Cave. J. Anthropol. Res. 65: 69-102.

Marín-Arroyo, A. B. (2009b) A practical comparative study of the available analytic techniques for skeletal part profile interpretation at El Mirón Cave (Cantabria, Spain). Archaeofauna 18: 79-98.

Marín-Arroyo, A. B. (2009c) The use of Optimal Foraging Theory to estimate Late Glacial site catchment areas from a central place. The case of eastern Cantabria, Spain. J. Anthropol. Archaeol. 28: 27-36

Marín-Arroyo, A. B. (2010) Arqueozoologia en el Cantábrico Oriental durante la transición Pleistoceno/Holoceno. La Cueva del Mirón. Santander, Spain: Publican.

Marín-Arroyo, A. B. and Margalida, A. (2012) Distinguishing Bearded vulture activities within archaeological contexts: identification guidelines. Int. J. Osteoarchaeol. 22: $563-576$.

Marín-Arroyo, A. B., Fosse, F. and Vigne, J. D. (2009) Probable evidences of bone accumulation by Pleistocene bearded vulture at the archaeological site of El Mirón Cave (Spain). J. Archaeol. Sci. 36: 284-296.
Martínez-Abraín, A., Crespo, J., Jiménez, J., Gómez, J. A. and Oro, D. (2009) Is the historical war against wildlife over in southern Europe? Anim. Conserv. 12: 204-208.

Morin, E. (2007) Fat composition and Nunamiut decision-making: a new look at the marrow and bone grease indices. J. Archaeol. Sci. 34: 69-82.

Naidoo, V., Wolker, K., Cuthbert, R. and Duncan, N. (2009) Veterinary diclofenac threatens Africa's endangered vulture species. Regul. Toxicol. Pharmacol. 53: 205-208.

Newsome, S. D., Collins, P. W., Rick, T. C., Guthrie, D. A., Erlandson, J. M. and Fogel, M. L. (2010) Pleistocene to historic shifts in bald eagle diets on the Channel Islands, California. Proc. Nat. Acad. Sci. USA 107: 9246-9251.

Thibault, J. C., Vigne, J. D. and Torre, J. (1993) The diet of young lammergeiers Gypaetus barbatus in Corsica: its dependence on extensive grazing. Ibis 135: 42-48.

Virani, M. Z., Kendall, C., Njoroge, P. and Thomsett, S. (2011) Major declines in the abundance of vultures and other scavenging raptors in and around the Masai Mara ecosystem, Kenya. Biol Conserv. 144: 746-752.

Willis, K. J. and Birks, H. J.B. (2006) What is natural? The need for a long-term perspective in biodiversity conservation. Science 314: 1261-1265.

Zeder, M. (2008) Domestication and early agriculture in the Mediterranean Basin: Origins, diffusion, and impact. Proc. Nat. Acad. Sci. USA 105: 11597-11604.

\section{ANTONI MARGALIDA*}

Bearded Vulture Study and Protection Group. Apdo. 43 E-25520 El Pont de Suert (Lleida), Spain; and Division of Conservation Biology, Institute of Ecology and Evolution, University of Bern, Baltzerstrasse 6, 3012, Bern, Switzerland.

ANA B. MARÍN-ARROYO

Instituto Internacional de Investigaciones Prehistóricas de Cantabria. Universidad de Cantabria. 39005, Santander, Spain.

${ }^{*}$ Author for correspondence; email: antoni.margalida@iee.unibe.ch

Received 2 July 2012; revision accepted 8 August 2012; Published online 28 March 2013 